\title{
Severidade de antracnose e crestamento bacteriano comum em feijoeiro sob diferentes espaçamentos e população de plantas
}

\section{Anthracnose severity in common bacterial blight in bean under different spacing and plant population}

\author{
Luis Osmar Braga Schuch ${ }^{1}$;rajá Ferreira Antunes ${ }^{2}$; Marcos Paulo Ludwig ${ }^{3}$;Sandro de Oliveira ${ }^{4 *}$; Elisa Souza Lemes ${ }^{5}$
}

Resumo: O feijão (Phaseolus vulgaris L.) tem grande importância econômica e social no Brasil fazendo parte da alimentação básica. A incidência de doenças foliares causa prejuízos à lavoura. O objetivo do trabalho foi avaliar a severidade de Antracnose e Crestamento Bacteriano Comum em feijoeiro sob diferentes espaçamentos e populações de plantas. Os experimentos foram conduzidos na área experimental do Centro Agropecuário da Palma, da Universidade Federal de Pelotas,

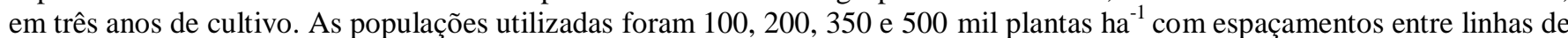
25,50 e $75 \mathrm{~cm}$. As avaliações foram realizadas nas vagens e folhas quando as plantas se encontravam no estágio R8. A severidade do Crestamento Bacteriano Comum e da Antracnose é variável de acordo com o ano de cultivo. A severidade do Crestamento bacteriano é mais afetada pela população de plantas do que pelo espaçamento. Menores espaçamentos entre linha, associados a maiores populações de plantas proporcionam um fechamento do solo mais rápido o que resulta em uma condição mais propícia ao desenvolvimento das doenças. A distribuição uniforme das plantas na área reduz a severidade de doenças.

Palavras-chave: Phaseolus vulgaris; Doenças de plantas; Colletotrichum lindemuthianum; Xanthomonas campestri.

\begin{abstract}
The beans (Phaseolus vulgaris L.) has great economic and social importance in Brazil as part of the basic food. The incidence of leaf diseases cause damage to crops. The objective was to evaluate the severity of Anthracnose and Bacterial blight common in bean under different spacing and plant populations. The experiments were conducted in the experimental area of Agricultural Center of Palma, the Federal University of Pelotas, in three years of cultivation. The populations used were $100,200,350$ and 500 thousand plants ha $^{-1}$ with spacings of 25,50 and $75 \mathrm{~cm}$. The evaluations were conducted in the pods and leaves when the plants were in the R8 stage. During cultivation of the crop the severity of the bacterial blight is higher than in the second crop, whilst the severity of injury is greater in the second crop. The severity of the common bacterial blight and anthracnose varies according to the year of cultivation. Smaller spacings between rows associated with larger populations of plants provide a faster closure of soil which results in a more favorable condition for the development of disease. The uniform distribution of plants in the area reduces disease severity.
\end{abstract}

Key words: Phaseolus vulgaris; Diseases; Colletotrichum lindemuthianum; Xanthomonas campestri.

\footnotetext{
*Autor para correspondência

Recebido para publicação em 22/11/2016; aprovado em 09/06/2017

${ }^{1}$ Dr. Engenheiro Agrônomo, Professor da Universidade Federal de Pelotas. E-mail: lobs@ufpel.edu.br

${ }^{2}$ Dr. Engenheiro Agrônomo, Pesquisador Embrapa Terras Baixas. E-mail: iraja.antunes @embrapa.br

${ }^{3}$ Dr. Engenheiro Agrônomo, Professor do Instituto Federal do Rio Grande do Sul. E-mail: marcos.ludwig@ibiruba.ifrs.edu.br

${ }^{4}$ Dr. Engenheiro Agrônomo. E-mail: sandrofaem@yahoo.com.br

${ }^{5}$ Dra. Engenheira Agrônoma, Bolsista PDJ CNPQ, Universidade Federal de Pelotas. E-mail: lemes.elisa@ yahoo.com.br
} 


\section{INTRODUÇÃO}

A cultura do feijoeiro (Phaseolus vulgaris L.) tem grande importância econômica e social no Brasil, pois faz parte da alimentação básica dos brasileiros, sendo cultivado cerca de 3,0 milhões de hectares, produzindo aproximadamente 3,3 milhões de toneladas, com um rendimento próximo de $1079 \mathrm{~kg} \mathrm{ha}^{-1}$ (CONAB, 2015). As causas da baixa produção podem estar relacionadas com extrema sensibilidade da cultura às variações climáticas, o uso de sementes com origem e qualidade desconhecidas, a implantação da cultura em solos com acidez elevada, a predominância de cultivos associados com outras culturas, a aplicação de quantidade insuficiente de fertilizantes, a população de plantas inadequada e a alta sensibilidade a pragas e doenças (JAUER et al., 2006).

O cultivo do feijoeiro normalmente é realizado em pequenas áreas, normalmente oriunda da agricultura familiar (EMBRAPA, 2013), no entanto nos últimos anos o interesse de grandes produtores pela cultura aumentou, isso deve-se principalmente, ao bom preço no mercado, época de cultivo e ciclo que permite a utilização da área para dois cultivos na mesma safra e pela utilização dos mesmos maquinários utilizados para outras culturas. Algumas regiões apresentam elevado potencial para a adoção da cultura do feijoeiro, como é o caso das regiões produtoras de trigo e soja, além da região de várzea do estado do Rio Grande do Sul.

A modernização do maquinário agrícola permite alterações do espaçamento e da densidade de semeadura de maneira simples, rápida e fácil. Estas alterações podem proporcionar mudanças no comportamento da cultura, podendo modificar tanto o crescimento como a produtividade. Trabalhando com diferentes populações de plantas de feijão, Jauer et al. (2003b) constataram que a maior produtividade foi obtida com uma população de plantas de 337 mil plantas ha $^{-1}$, que o aumento da população de plantas resultou em aumento na altura de inserção do primeiro legume, e que a partir de 400 mil plantas $\mathrm{ha}^{-1}$ reduziu o número de entrenós, observando ainda que as alturas de inserção do primeiro legume e da base do primeiro legume são adequadas para a colheita mecanizada. Jauer et al. (2003a) trabalhando com feijão (cultivar Iraî) não obtiveram diferenças no rendimento de grãos, no número de legumes, número de grãos legume ${ }^{-1}$, peso médio de 100 grãos e estatura de planta entre as populações testadas.

A cultura do feijoeiro é muito vulnerável a vários fitopatógenos, aliado as variações climáticas que favorecem a incidência e o desenvolvimento das doenças (PASSOS, 2016). Desta forma a incidência de doenças foliares e radiculares constituem um dos principais fatores que acarretam em baixas produtividades na cultura do feijoeiro (REY et al., 2005; BARROS \& SOUZA, 2012). Vários autores mencionam o efeito positivo da aplicação de fungicidas no controle de doenças, (RAVA 2002; JAUER et al. 2006). Em trabalho com diferentes populações de plantas e tratamentos fitossanitários Jauer et al. (2006) constataram que as maiores populações de plantas apresentaram rendimentos superiores ou equivalentes aos obtidos na menor população de plantas, e que a ocorrência de moléstias não acarretou redução do rendimento de grãos nas populações maiores. No entanto, para que a cultura continue sendo atrativa para os produtores, melhorias devem ser realizadas para aumentar o potencial de rendimento das cultivares de feijoeiro.
Desta forma, o melhorando genético busca obter cultivares mais resistentes a doenças e pragas, que sejam mais produtivas e que possibilitem a realização da colheita mecanizada, o que, aliado a técnicas adequadas de cultivo para a cultura, como espaçamento e população de plantas, possam resultar em maior potencial produtivo. A adequação do espaçamento entre linhas e das plantas na linha, aliadas a uma adequada população resultará em melhor arranjo espacial das plantas na lavoura, o que permite melhor aproveitamento dos recursos disponíveis, possibilitando melhor expressão do potencial genético das cultivares. Dessa forma, cultivares promissores podem ter sido descartados, por não terem sido avaliados de forma adequada quanto ao arranjo espacial (ZIVIANI et al., 2009).

Diante disto, objetivou-se avaliar a severidade do ataque de Antracnose e Crestamento Bacteriano Comum em feijoeiro (Phaseolus vulgaris L.) submetido a diferentes espaçamentos e populações de plantas.

\section{MATERIAL E MÉTODOS}

Os experimentos foram conduzidos em condições de campo na área experimental do Centro Agropecuário da Palma (CAP), da Universidade Federal de Pelotas (UFPel), município de Capão do Leão, Rio Grande do Sul, em três anos de cultivo, seguindo as principais recomendações para o cultivo do feijoeiro. $\mathrm{O}$ solo da área experimental é classificado como Planossolo Hidromórfico Eutrófico Solódico, pertencente à Unidade de Mapeamento Pelotas (STRECK et al., 2008).

Foram utilizadas populações de 10, 20, 35 e 50 plantas por $\mathrm{m}^{2}$, com os espaçamentos entre linhas de 25,50 e $75 \mathrm{~cm}$, sendo as parcelas compostas por 11, 6 e 5 linhas de 4 metros de comprimento, respectivamente, utilizando como área útil de cada parcela 5,25, 6,00 e $6,75 \mathrm{~m}^{2}$, sendo o restante da parcela considerada como bordadura. Para obtenção das populações de plantas após a emergência das plântulas foi realizado desbaste. $\mathrm{O}$ delineamento experimental foi um tri fatorial $3 \times 4 \times 3$ (estação de cultivo $x$ populações de plantas $x$ espaçamentos) distribuído em blocos casualizados, com quatro repetições. Usou-se a cultivar de feijão Pampa, a qual é de grão preto, que apresenta hábito de crescimento indeterminado.

Foram realizadas avaliações de severidade das doenças Antracnose (Colletotrichum lindemuthianum) e Crestamento Bacteriano Comum (Xanthomonas campestri) nas vagens e nas folhas quando as plantas se encontravam no estágio R8 (FERNANDEZ et al., 1986). As avaliações foram realizadas, utilizando as escalas para avaliação de moléstias a campo conforme descritas por Rava et al. (1988), a qual considera a porcentagem e a extensão da lesão da doença causada nas folhas, nervuras e legumes das plantas atacadas.

Foi realizada a avaliação de fechamento entre linhas (cobertura do solo pelas plantas). Estas avaliações ocorriam semanalmente até que o solo ficasse com superfície coberta superior a $95 \%$.

Todas as variáveis foram submetidas à análise da variância para verificar os efeitos dos tratamentos e se significativo os desdobramentos foram realizados por regressão polinomial ou teste de média por Tukey, ambos a $5 \%$ de probabilidade. As análises estatísticas foram realizadas através do programa estatístico SISVAR (FERREIRA, 2011). 


\section{RESULTADOS E DISCUSSÃO}

A severidade de antracnose na folha (Figura 1) apresentou interação tripla entre estação de cultivo $\mathrm{x}$ populações de plantas $\mathrm{x}$ espaçamentos. No entanto no segundo ano de cultivo o valor de severidade foi igual a 1 (Figura 1A). No primeiro ano de cultivo para o espaçamento de $75 \mathrm{~cm}$ a maior severidade foi observada na população de plantas de 39 plantas por $\mathrm{m}^{2}$, sendo que a partir dessa praticamente se manteve até a maior população. No espaçamento de $50 \mathrm{~cm}$ foi observado maior severidade da doença na maior população estudada, sendo que no espaçamento de $25 \mathrm{~cm}$ foi observado aumento da severidade até a população de 35 planta por $\mathrm{m}^{2}$, sendo que a partir dessa população houve decréscimo da severidade da doença. No primeiro ano de cultivo foram observados os maiores valores de severidade de antracnose na folha, resultado que pode estar relacionado com a característica de desenvolvimento do patógeno, pois áreas com condições ambientais favoráveis como temperaturas moderadas entre $14{ }^{\circ} \mathrm{C}$ a $20{ }^{\circ} \mathrm{C}$ (ROSOLEM; MARUBAYASHI, 1994) e alta umidade relativa entre 90 e $96 \%$ (VECHIATO et al., 1997), favorecem o desenvolvimento do fungo, o que é comum no final do ciclo da cultura. Este resultado também é observado para a Antracnose nas vagens, onde se observou maior severidade.

No primeiro ano de cultivo, com alta pressão do patógeno o espaçamento de $50 \mathrm{~cm}$, aproximadamente até a população de 35 planta por $\mathrm{m}^{2}$ apresentou menor incidência da doença. As maiores incidências da doença foram obtidas no maior espaçamento em todas as populações de plantas. Resultado que pode estar relacionado à distribuição das plantas na linha, pois nesta condição de cultivo as plantas ficam mais próximas o que pode acarretar maior competição pelos fatores de produção, resultando em plantas mais suscetíveis. Além disso, a proximidade das plantas também pode formar um microclima mais favorável ao desenvolvimento da doença. Resultado que também ocorre com a severidade de antracnose no terceiro ano de cultivo (Figura 1B) onde no maior espaçamento $(75 \mathrm{~cm})$ o aumento do número de plantas na linha, ocasionou elevação na severidade da doença. Segundo Costa et al. (2002), espaçamentos com entre linhas reduzidos poderiam ser favoráveis à menor ocorrência de doenças pois nestes há maior aeração em função de maior circulação do vento, tanto na direção transversal como longitudinal das linhas devido ao fato das plantas estarem melhor arranjadas.

No terceiro ano de cultivo os valores de severidade foram superiores ao do segundo ano, mas inferiores os do primeiro. Para esta condição a menor severidade foi obtida no espaçamento de $75 \mathrm{~cm}$ e na população de 20 plantas por $\mathrm{m}^{2}$. No espaçamento de $25 \mathrm{~cm}$ a menor incidência foi constatada na densidade de 50 plantas por $\mathrm{m}^{2}$ e no espaçamento de $50 \mathrm{~cm}$ na população de 10 plantas por $\mathrm{m}^{2}$. Nestas condições para se definir o melhor espaçamento e a população de plantas, outras características necessitam ser levadas em conta, tais como, tamanho da propriedade e da área a ser cultivada, disponibilidade de semeadora que possibilite as regulagens e a possibilidade de colheita mecânica. Jauer et al. (2003) menciona que partir de 400 mil plantas ha $^{-1}$, as alturas de inserção do primeiro legume e da base do primeiro legume ajustam-se ao necessário para a colheita mecanizada, em um espaçamento de $40 \mathrm{~cm}$. Em relação ao controle da antracnose Rey et al. (2005), explica que este pode ser atingido através de um conjunto de medidas que dizem respeito a práticas culturais, químicas, além do uso de cultivares geneticamente resistentes, sendo estas medidas executadas de forma integrada e com caráter preventivo, assim o ajuste da população de plantas e do espaçamento pode contribuir para a redução da doença.

Figura 1. Notas de severidade de antracnose na folha em quatro populações de plantas $\left(10,20,35\right.$ e 50 plantas por $\left.\mathrm{m}^{2}\right)$ e três espaçamentos entre linha $(25,50$ e $75 \mathrm{~cm})$ em três anos de cultivos, cultivados no Centro Agropecuário da Palma (CAP-UFPel), Capão do Leão, Rio Grande do Sul
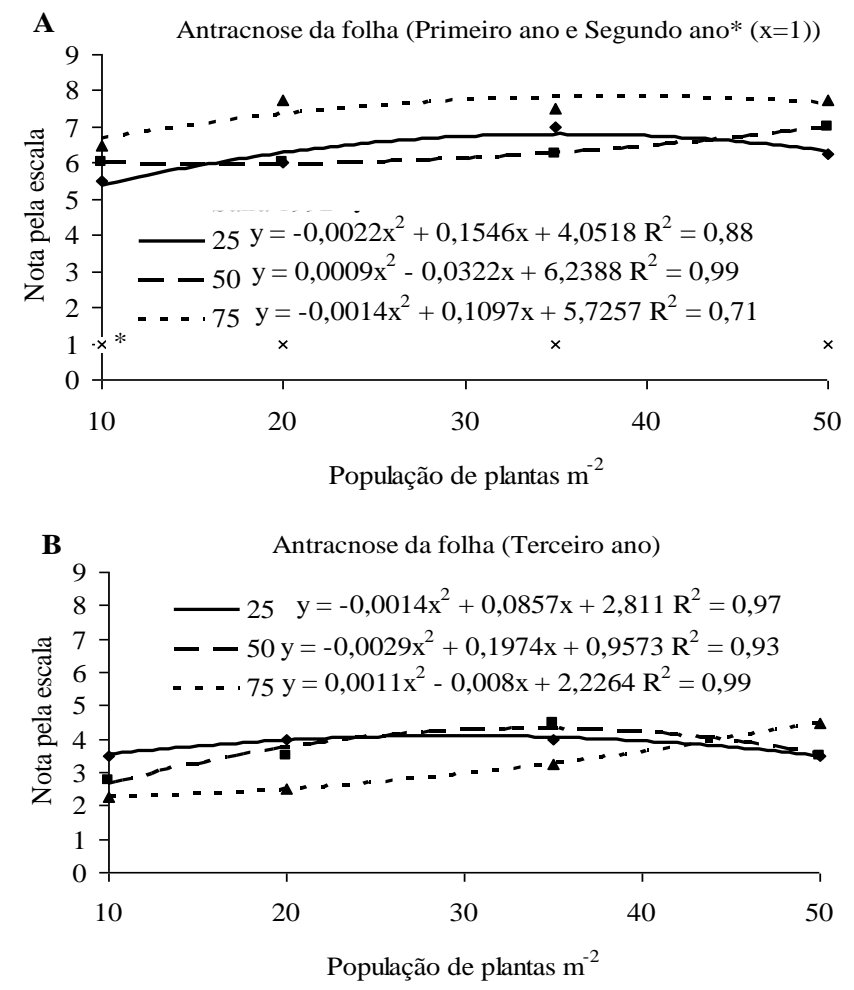

A severidade de antracnose na vagem foi afetada pela população de plantas (Figura 2), sendo o maior índice de severidade da doença foi obtido na maior população de plantas. A estação de cultivo com maior severidade foi no primeiro ano de cultivo, seguido pelo terceiro ano e pelo segundo ano de cultivo (Tabela 1). Estes resultados podem estar relacionados com as condições ambientais em cada ano de cultivo, pois estas variam muito de um ano para outro.

Figura 2. Notas de severidade de antracnose na vagem em quatro populações de plantas $\left(10,20,35\right.$ e 50 plantas por $\left.\mathrm{m}^{2}\right)$ e três espaçamentos entre linha $(25,50$ e $75 \mathrm{~cm})$ média de três anos de cultivos, cultivados no Centro Agropecuário da Palma (CAP-UFPel), Capão do Leão, Rio Grande do Sul

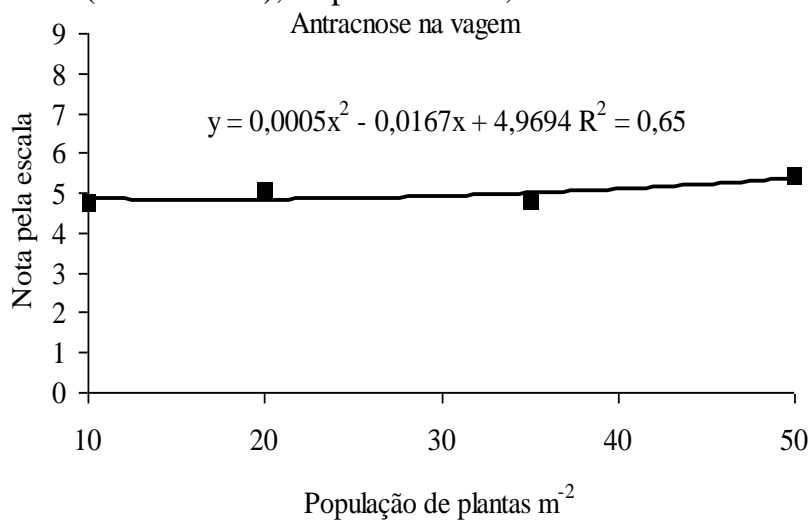


Os resultados de severidade do Crestamento Bacteriano Comum mostraram não haver efeito do espaçamento, resultados estes que indicam que a severidade da bacteriose é mais afetada pela população de plantas que pelo espaçamento. Para o Crestamento Bacteriano Comum na folha (Figura 3A), os resultados das notas de severidade, para as médias dos espaçamentos, enquadraram-se num modelo polinomial quadrático positivo, sendo observado maior valor na população de 48 plantas por $\mathrm{m}^{2}$. O Crestamento Bacteriano Comum na vagem (Figura 3B), a maior nota de severidade da doença foi obtida numa população de 42 plantas por $\mathrm{m}^{2}$, na média dos espaçamentos. Desta forma, pode ser notado que a alta densidade de plantas geralmente pode resultar em maior sensibilidade das plantas de feijoeiro as doenças, possivelmente devido à formação de um microclima favorável, e por ao mesmo tempo facilitar a disseminação dos propágulos dos patógenos entre as plantas.

Figura 3. Notas de severidade de crestamento bacteriano na folha (A) e de crestamento bacteriano na vagem (B) em quatro populações de plantas $\left(10,2035\right.$ e 50 plantas por $\left.\mathrm{m}^{2}\right)$ na média de três espaçamentos entre linha $(25,50$ e $75 \mathrm{~cm})$ em três anos de cultivos, cultivados no Centro Agropecuário da Palma (CAP-UFPel), Capão do Leão, Rio Grande do Sul
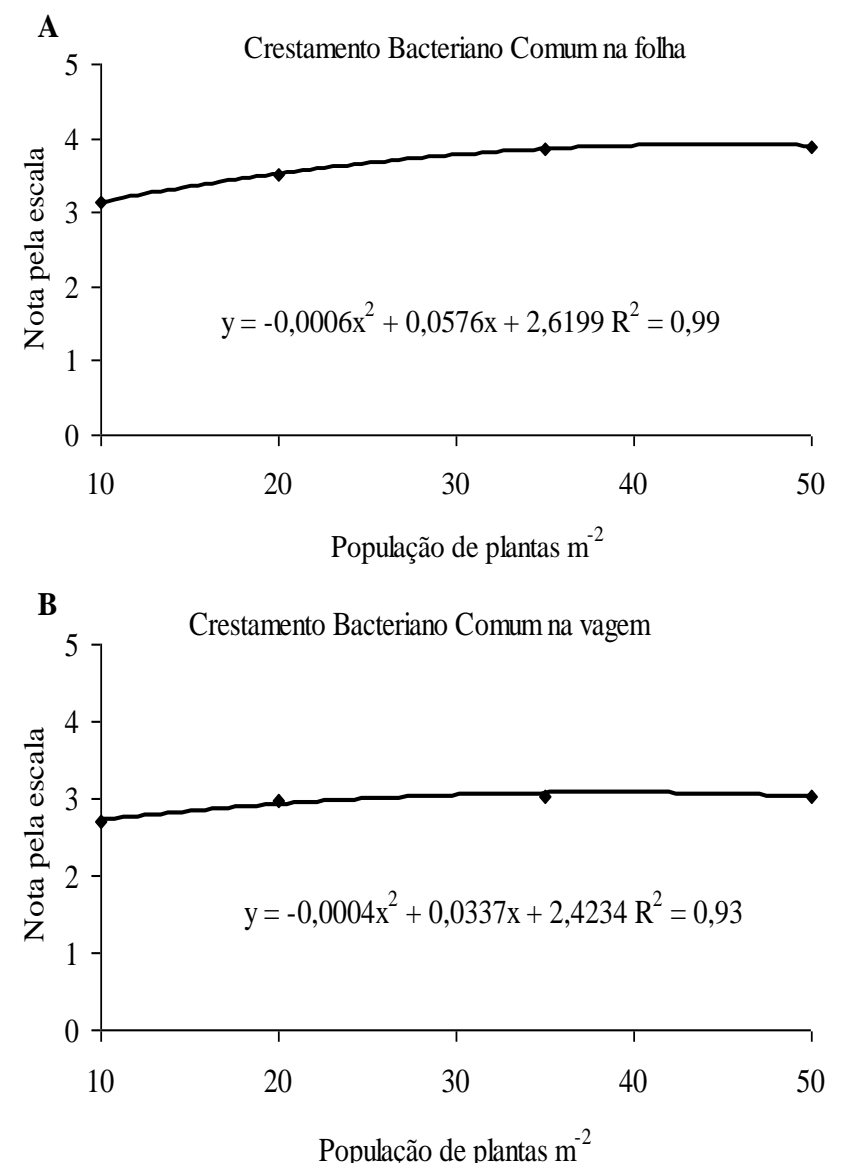

Os resultados anteriormente discutidos, podem também estar relacionados com os resultados referente ao fechamento do solo (Figura 4), pois as maiores populações proporcionam um fechamento do solo mais rápido. Argumentação citada por Costa et al. (2002) explica que com a cobertura mais rápida do solo, há uma condição mais propícia (umidade no interior do dossel) ao desenvolvimento das doenças. Knebel et al. (2006), trabalhado com soja, constataram que a incidência de doenças de final de ciclo pode ser influenciada pelo arranjo espacial de plantas, apresentando menor severidade de doenças com a redução do espaçamento e em menores populações. O que ressalta a importância da distribuição uniforme das plantas na área, podendo reduzir a severidade de doenças.

Figura 4. Dias após a emergência em que ocorreu o fechamento entre linhas em quatro populações de plantas (10, 20,35 e 50 plantas por $\mathrm{m}^{2}$ ) em três espaçamentos entre linha $(25,50$ e $75 \mathrm{~cm})$, média de três anos de cultivos, cultivados no Centro Agropecuário da Palma (CAP-UFPel), Capão do Leão, Rio Grande do Sul

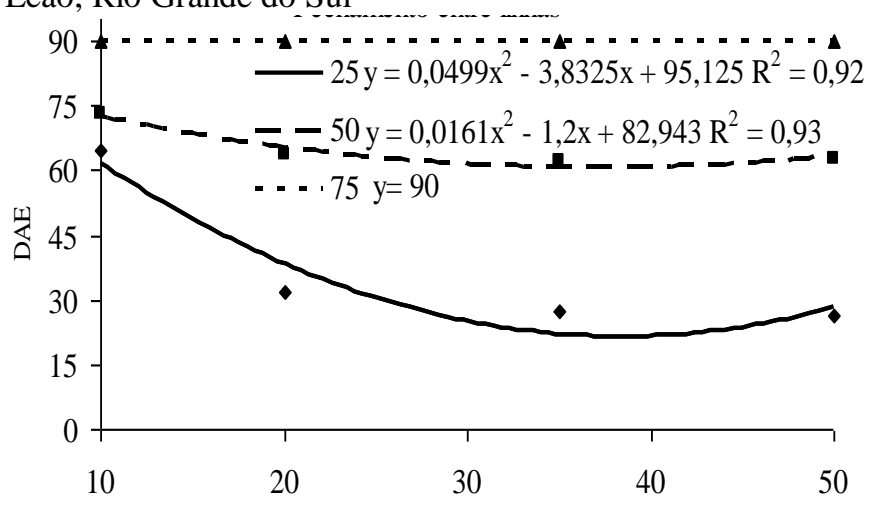

População de plantas $\mathrm{m}^{-2}$

Em relação às notas de severidade de antracnose na vagem nas diferentes épocas de cultivo (Tabela1), o primeiro ano de cultivo apresentou maior valor, sendo que o segundo ano de cultivo obteve o menor valor. Com relação ao crestamento bacteriano comum na folha e na vagem, nas diferentes épocas de cultivo (Tabela 1), apresentou no primeiro ano de cultivo os menores valores de severidade, sendo que no terceiro ano de cultivo foi obtido os maiores valores de severidade. As maiores notas de severidade na safra estão relacionadas as condições mais propicias para o desenvolvimento da bactéria que são alta temperatura e elevada umidade relativa (ROSOLEM; MARUBAYASHI, 1994), condição que é observada no cultivo da safra no Rio Grade do Sul.

O número de dias após a emergência em que ocorreu o fechamento do solo (Tabela 1), nas diferentes condições de cultivo indica que o espaçamento entre linha de $75 \mathrm{~cm}$ não propicia fechamento do solo em nenhuma das épocas de cultivo, o que proporciona condição de aeração da área. No entanto quando ocorre o aumento da população de plantas neste espaçamento ocorre aumento da nota de severidade de antracnose na folha no primeiro e no terceiro ano de cultivo. Os espaçamentos de 25 e $50 \mathrm{~cm}$, apresentaram variações no número de dias após a emergência até que ocorresse o fechamento do solo, sendo que em ambos espaçamentos o segundo ano de cultivo foi o que teve o maior número de dias para se ter o fechamento do solo, seguido pelo terceiro ano de cultivo. Como já se podia esperar, os menores espaçamentos entre linha proporcionaram o fechamento do solo mais rápido. 
Tabela 1. Notas de severidade de antracnose na vagem (AV), crestamento bacteriano na folha $(\mathrm{CBF})$, crestamento bacteriano na vagem (CBV) e número de dias após emergência em que ocorreu o fechamento do solo em três anos de cultivos, na média de quatro populações de plantas $\left(10,2035\right.$ e 50 plantas por $\left.\mathrm{m}^{2}\right)$ e três espaçamentos entre linha $(25,50$ e $75 \mathrm{~cm})$, cultivado no Centro Agropecuário da Palma (CAP-UFPel), Capão do Leão, Rio Grande do Sul

\begin{tabular}{cccc}
\hline Cultivo & AV & CBF & CBV \\
\hline Primeiro ano & $6,7 \mathrm{a}$ & $1,00 \mathrm{c}$ & $1,00 \mathrm{c}$ \\
Segundo ano & $3,1 \mathrm{c}$ & $3,15 \mathrm{~b}$ & $3,21 \mathrm{~b}$ \\
Terceiro ano & $5,2 \mathrm{~b}$ & $6,65 \mathrm{a}$ & $4,58 \mathrm{a}$ \\
\hline \multicolumn{4}{c}{ DAE } \\
\hline Espaçamento & Primeiro ano & Segundo ano & Terceiro ano \\
\hline 25 & $28 \mathrm{cB}$ & $48 \mathrm{bA}$ & $37 \mathrm{cB}$ \\
50 & $46 \mathrm{bC}$ & $90 \mathrm{aA}$ & $60 \mathrm{bB}$ \\
75 & $90 \mathrm{aA}$ & $90 \mathrm{aA}$ & $90 \mathrm{aA}$ \\
\hline
\end{tabular}

*Médias seguidas por letras distintas, minúscula na coluna e maiúscula na linha, diferem pelo teste de Tukey, a 5\% de probabilidade de erro.

\section{CONCLUSÕES}

A severidade do Crestamento Bacteriano Comum e da Antracnose varia de acordo com o ano de cultivo. A severidade do Crestamento bacteriano é mais afetada pela população de plantas do que pelo espaçamento das linhas.

Menores espaçamentos entre linha, associados a maiores populações de plantas proporcionam um fechamento do solo mais rápido o que resulta numa condição mais propícia ao desenvolvimento das doenças.

A distribuição uniforme das plantas na área reduz a severidade de doenças.

\section{REFERÊNCIAS}

COSTA, J. A. Redução no espaçamento entre linhas e potencial de rendimento da soja. Revista Plantio Direto, 22$28,2002$.

EMBRAPA. Informações Técnicas para o cultivo do Feijoeiro Comum na Região Nordeste Brasileira 2012-2014Documentos 181, Aracaju, 2013.

FERREIRA, D. F. Manual do sistema Sisvar para análises estatísticas. Universidade Federal de Lavras, Departamento Ciências Exatas, Lavras, 2000, p.69.

FERNANDEZ, F.; GEPTS, P.; LOPEZ, M. Etapas de desarollo de la planta de fríjol común (Phaseolus vulgaris L.). Cali, Colômbia: CIAT, 1986.

JAUER, A.; DUTRA, L. M. C.; ZABOT, L.; UHRY, D.; LUDWIG, M. P.; FARIAS, J. R.; GARCIA, D. C.; LUCIO, A. D. C.; LUCCA FILHO, O. A.; PORTO, M. D. M. Efeitos da população de plantas e de tratamento fitossanitário no rendimento de grãos do feijoeiro comum, cultivar "TPS Nobre”. Ciência Rural, v. 6, n. 5, p. 1374-1379, 2006.

JAUERR, A.; DUTRA, L. M. C.; LUCCA FILHO, O. A.; SANTI, A. L.; ZABOT, L.; UHRY, D.; BONADIMAN, R.; BELLÉ, G.; LUCIO, A. D. C. Rendimentos de grãos, seus componentes e características morfológicas do feijoeiro comum cultivado em quatro densidades de semeadura na safrinha. Ciência Rural, v. 33, n. 1, p. 21-26, 2003a.

JAUER, A.; DUTRA, L. M. C.; LUCCA FILHO, O. A.; SANTI, A. L.; ZABOT, L.; UHRY, D.; BONADIMAN, R.; BELLÉ, G.; LUCIO, A. D. C. Comportamento da cultivar BR-IPAGRO 44-guapo brilhante de feijoeiro em quatro populações de plantas na safrinha em Santa Maria-RS. Ciência Rural, v. 33, v. 2, p. 201-206, 2003 b.

KNEBEL, J. L.; GUIMARÃES, V. F.; ANDREOTTI, M.; STANGARLIN, J. R. Influência do espaçamento e população de plantas sobre doenças de final de ciclo e oídio e caracteres agronômicos em soja. Acta Scientiarum. Agronomy, v. 28, n. 3, p. 385-392, 2006.

PASSOS, A. L. P. Mapeamento de locos de resistência ao Crestamento Bacteriano Comum do Feijoeiro (Fhaseolus vulgaris L.). 2016. 81p. Dissertação (Mestrado) - Programa de Pós-Graduação em Genética e Melhoramento de Planas. Universidade Federal de Goiás, Goiânia.

RAVA, C. A. Eficiência de fungicidas no controle da antracnose e da mancha angular do feijoeiro comum. Summa Phytopathologica, v. 8, n. 1, p. 65-69, 2002.

REY, M. S.; BALARDIN, R. S.; PIEROBOM, C. R. 2005. Reação de cultivares de feijoeiro comum (Phaseolus vulgaris) a patótipos de Colletotrichum lindemuthianum. Revista Brasileira de Agrociência, v. 11, n. 1, p. 113-116, 2005.

ROSOLEM, C. A.; MARUBAYSHI, O. M. Seja o doutor do seu feijoeiro. Informações Agronômicas. 68 p. 18, 1994.

VECHIATO, M. H.; KOHARA, E. Y.; MENTEN, J. O. M. Transmissão de Colletotrichum indemuthianum em sementes de feijoeiro comum. Summa Phytopathologica, v. 23, p. 265269, 1997.

ZIVIANI, A. C.; RIBEIRO JÚNIOR, W. Q.; RARMOS, M. L. G.; BARBOSA, M. A. A. F.; CORDEIRO, A.; FRANÇA, L.V. Arranjos espaciais de feijoeiro de portes contrastantes e seus efeitos na produtividade e cobertura vegetativa. Bioscience Journal, v. 25, n. 2, p.1-9, 2009.

STRECK, E. V.; KÄMPF, N.; DALMOLIN, R. S. D.; KLAMT, E., NASCIMENTO, P. C.; SCHNEIDER, P.; GIASSON, E. PINTO, L. F. S. Solos do Rio Grande do Sul. 2.ed. Porto Alegre, EMATER/RSASCAR, p. 222, 2008.

COMPANHIA NACIONAL DE ABASTECIMENTO CONAB. 2015. Acompanhamento de safra brasileira: sexto levantamento grãos safra 2014/2015, Brasília, Observatório Agrícola, p. 1-107, 2015. Disponível em: <http://www.conab.gov.br/OlalaCMS/uploads/arquivos/15_0 8_11_08_55_08_boletim_graos_agosto_2015.pdf>. Acesso em: 13 nov. 2015 .

RAVA, C. A.; COSTA, J. G. C.; SARTORATO, A.; PURISSOMO, J. D. Catálogo do feijoeiro comum (Phaseolus vulgaris L.): reação de linhagens e cultivares às principais doenças. Goiânia: EMBRAPA-CNPAF, 122p. 1988. 